\title{
Application of the Takaga-Sugeno neuro-fuzzy model for determining of engineering structures
}

\author{
Maria Mrówczyńska ${ }^{1, *}$ \\ ${ }^{1}$ University of Zielona Góra, Faculty of Civil Engineering, Architecture and Environmental \\ Engineering, ul. Prof. Z. Szafrana 1, 65-516 Zielona Góra, Poland
}

\begin{abstract}
The objective of the paper is to show the role of geodetic monitoring and modern methods of measurement data processing with the use of neural-fuzzy systems in identifying changes occurring in engineering structures. Fast methods of measurement and data processing are of key importance whenever rapidly changing phenomena should be captured (e.g. deformations of buildings, fires spreading in forest areas, flood waves, landslides caused by endogenous and exogeonic factors). Processes and phenomena occurring in engineering structures can be modelled based on information obtained by geodetic monitoring. At present, elements of geodetic technologies are being supplemented with artificial intelligence methods, which include neuro-fuzzy systems. These systems can process information that is provided at the input both as numerical and linguistic values. This approach is used for qualitative assessment of the condition of objects and physical quantities and it is characterized by parallel information processing. The paper presents the possibility of using the Takaga-Sugeno neural-fuzzy model for prediction and assessment of horizontal and vertical displacements of engineering structures as illustrated by the example of a historical footbridge in Muskauer Park, located in Germany and Poland.
\end{abstract}

\section{Introduction}

At the design phase of engineering structures, it is difficult to predict which factors will affect their stability in the future. The factors that affect the strength of engineering structures and their substrate include: construction and assembly errors, hidden material defects, changes in hydrogeological conditions of the substrate, effects of long- and short-term loads, endogenous (tectonic) motions, exogenous motions (wind, human activity, water, sun). Over time, these factors may cause changes in the spatial position of structural elements, which prevents proper operation of the facility, poses a danger to the environment and may even lead to a construction disaster [1-3]. In order to counteract these phenomena and prevent possible disasters, it is necessary to determine displacements and deformations of engineering structures in the field. In the classical approach, geodetic monitoring is used to determine displacements and deformations, which provides information about the condition and behaviour of objects under the influence of various factors. Geodetic engineering measurements, both on land and water, can be performed using classical geodetic methods,

*Corresponding author: m.mrowczynska@ib.uz.zgora.pl 
methods based on satellite techniques and methods based on terrestrial or aerial laser scanning [4-9]. A particularly important problem is the right selection of measurement methods for registering rapid changes occurring in the object, in such a situation methods based on laser scanning are invaluable.

As a result of the development of information technology, methods of acquiring measurement data are changing but, more importantly, also methods of measurement data processing. Data processing has to bring adequately accurate and reliable results. Methods and tools based on GIS techniques and remote sensing are gaining in importance. They are used to aid classical geodetic calculations [10-13].

As far as modern information processing techniques are concerned, it is impossible to omit methods based on artificial intelligence, which uses knowledge of the structure and functioning of the human brain and nerve cells. Artificial intelligence, in particular neural networks and neuro-fuzzy systems, is used in different fields of knowledge because of its versatility, the ability to learn, to generalize acquired knowledge and to solve problems that are difficult to describe with a mathematical model $[14,15]$. One of the techniques of artificial intelligence, which can be used to solve problems in the field of construction, geodesy and engineering geodesy, including determination and prediction of displacements and deformations of engineering structures, is based on neural networks, networks with radial base functions and neuro-fuzzy systems [16-22].

Neuro-fuzzy systems were created by combining neural networks, which process information in numerical form, and fuzzy systems, which process information provided in the form of linguistic values and store it in the form of fuzzy rules [23-25]. The combination of neural networks and fuzzy systems makes it possible to process information stored in numerical and linguistic form. At the same time a network (system) created in this way has additional knowledge in the form of fuzzy rules and it can learn and generalize the acquired knowledge.

The paper presents the Takaga-Sugeno neuro-fuzzy model used for prediction of horizontal displacements observed on a historical footbridge in Muskauer Park, located in Germany and Poland. Application of this approach makes it possible to determine changes occurring in the object and the impact of measurement errors on the final result.

\section{Methods}

Neural networks are neurons that are properly connected by means of synaptic connections represented by weights and arranged in two or more layers. In multi-layer neural networks, there are at least two layers: the input layer and the output layer, there may be hidden layers between them (Fig. 1). Neural networks are most often built of sigmoidal neurons (continuous neurons), for which nonlinear activation functions $f(n e t)$ can be defined based on a number of dependencies, several of which are presented in Table 1.

In order to correctly process information, neural networks have to undergo a training process during which the weights of synaptic connections are modified. In most cases, gradient optimization methods are used during the training process (the Levenbeg-Marquardt method of steepest descent, methods of variable metrics and conjugate gradients) [26]. 
Table 1. Non-linear activation functions.

\begin{tabular}{|c|c|}
\hline $\begin{array}{c}\text { Non-linear activation } \\
\text { function }\end{array}$ & Mathematical notation \\
\hline $\begin{array}{c}\text { bipolar function (hyperbolic } \\
\text { tangent) }\end{array}$ & $y=f(n e t)=\frac{1-\exp (-\lambda n e t)}{1+\exp (-\lambda n e t)}$ \\
\hline $\begin{array}{l}\text { unipolar function (logistic } \\
\text { function) }\end{array}$ & $y=f(n e t)=\frac{1}{1+\exp (-\lambda n e t)}$ \\
\hline sine function & $y=f(n e t)=\sin (\lambda n e t)$ \\
\hline sigmoidal function & $y=f(n e t)=\frac{\lambda n e t}{\sqrt{1+\lambda^{2} n e t^{2}}}$ \\
\hline \multicolumn{2}{|c|}{$\begin{array}{l}\text { where: } \\
\lambda \text { - the slope coefficient of the activation function } \\
\text { net } \stackrel{\text { def }}{=}\left[\mathbf{w}^{T} \mathbf{x}\right] \text { - the output signal of the linear part of a neuron } \\
\mathbf{w}-\text { the weight vector } \\
\mathbf{x} \text { - the input vector }\end{array}$} \\
\hline
\end{tabular}

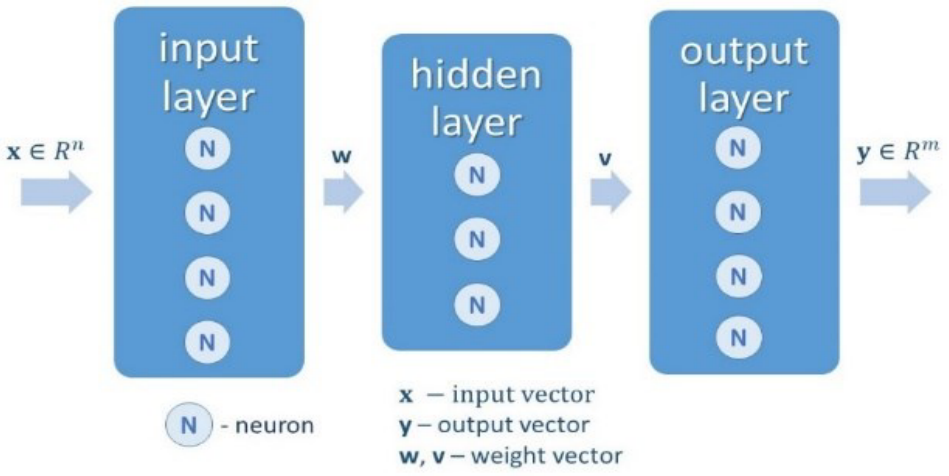

Fig. 1. A diagram of a multilayer neural network, prepared by the author.

A fuzzy inference system consists of a set of fuzzy rules, a database described by membership functions and an inference and aggregation mechanism. In the case of engineering applications such as geodetic measurements, the data forming the input set (x) and the output set (y) are measured values, which strictly assign output data to input data [25]. In order to cause these two sets to cooperate with each other, it is necessary to introduce a fuzzifying block- a fuzzificator into the fuzzy system on the input, while on the output a sharpening block - a de-fuzzificator should be introduced. A diagram of a fuzzy inference system is shown in Fig. 2.

\section{Ruls}

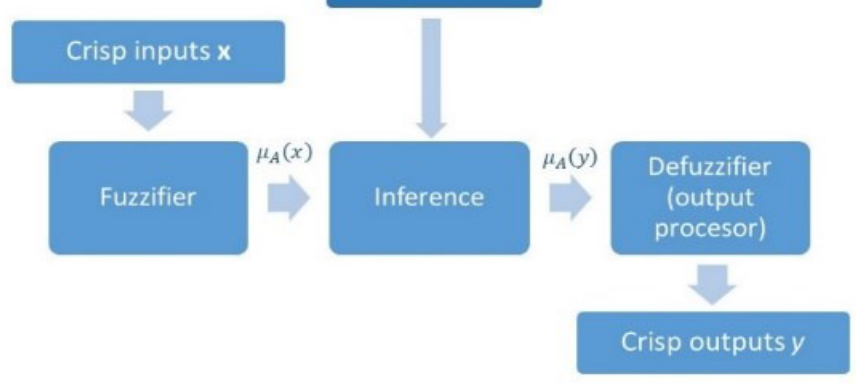

Fig. 2. A diagram of a fuzzy inference system, prepared by the author. 
The fuzzifying block has the task of transforming the input vector x into the fuzzy set $A$ in accordance with the adopted membership function $\mu_{A}(\mathbf{x})$, which can assume the form of a Gaussian function defined as:

$$
\mu_{A}(\mathbf{x})=\exp \left[-\left(\frac{x-c}{\sigma}\right)^{2}\right]
$$

where $x$ is a variable with the width $\sigma$ and the centre at $c$. The sharpening block transforms the fuzzy set into a single solution point, which can be done using the sharpening method and the average of the centres, then:

$$
y_{c}=\frac{\sum_{i=1}^{M} \mu\left(y_{c i}\right) y_{c i}}{\sum_{i=1}^{M} \mu\left(y_{c i}\right)}
$$

The symbols used in the formula (2) denote: $y_{c i}$ - the center of the $i$-th fuzzy rule, $\mu\left(y_{c i}\right) y_{c i}$ - the value of the membership function corresponding to the $i$-th rule, $M$ - the number of fuzzy rules.

By combining neural networks and fuzzy systems, we obtain neuro-fuzzy systems, of which the Takaga-Sugeno system is most frequently used for practical applications. Its diagram is presented in Fig. 3. In this model, the base of rules is fuzzy only in the "if" part whereas in the "then" part there are function dependencies:

$$
\text { IF ( } x_{1} \text { is } A_{1} \text { and } x_{2} \text { is } A_{2} \text { and } \ldots \text { and } x_{n} \text { is } A_{n} \text { THEN } y_{1}=f\left(x_{1}, x_{2}, \ldots, x_{\mathrm{n}}\right)
$$

A model created in this way uses a membership function defined in a sharp way, which makes it possible to simplify the model because the sharpening block is eliminated at the output. During the training process, $n$ training pairs $(\mathbf{x}, d)$ are mapped using the output function $y(\mathbf{x})$ so that the setpoint value $d$ best corresponds to the input value $x$. The training process itself consists in minimizing the objective function $E$ defined as:

$$
E=\frac{1}{2} \sum_{i=1}^{n}\left[y\left(\mathbf{x}_{i}\right)-d_{i}\right]^{2} \rightarrow \min
$$

using the error backpropagation method and gradient optimization methods.

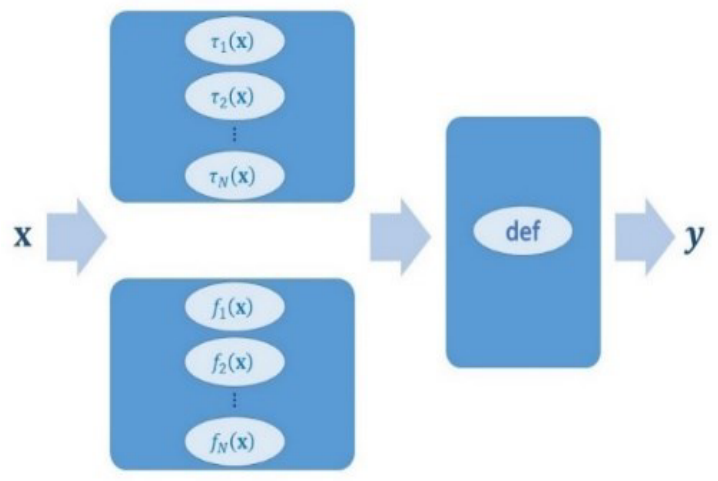

Fig. 3. The network structure of the Takaga-Sugeno inference system, prepared by the author, based on [23]. 


\section{Results}

Muskauer Park, founded at the beginning of the 19th by Hermann von Plückler and located in Germany and Poland (Lubusz Voivodeship), is one of the largest and most valuable landscape parks in Europe (Fig. 4). In the park, arranged in the English style, there are single artificial and natural objects such as buildings and structures, water reservoirs, erratic boulders, exposed lignite seams, and all these objects are connected with educational paths, hiking routes and cycle lanes [27]. One of the objects located in the park is a footbridge built of bricks with a characteristic sharp gate opening (Fig. 5). The footbridge was subjected to cyclical geodetic measurements because of cracks, which indicated displacements occurring in it.

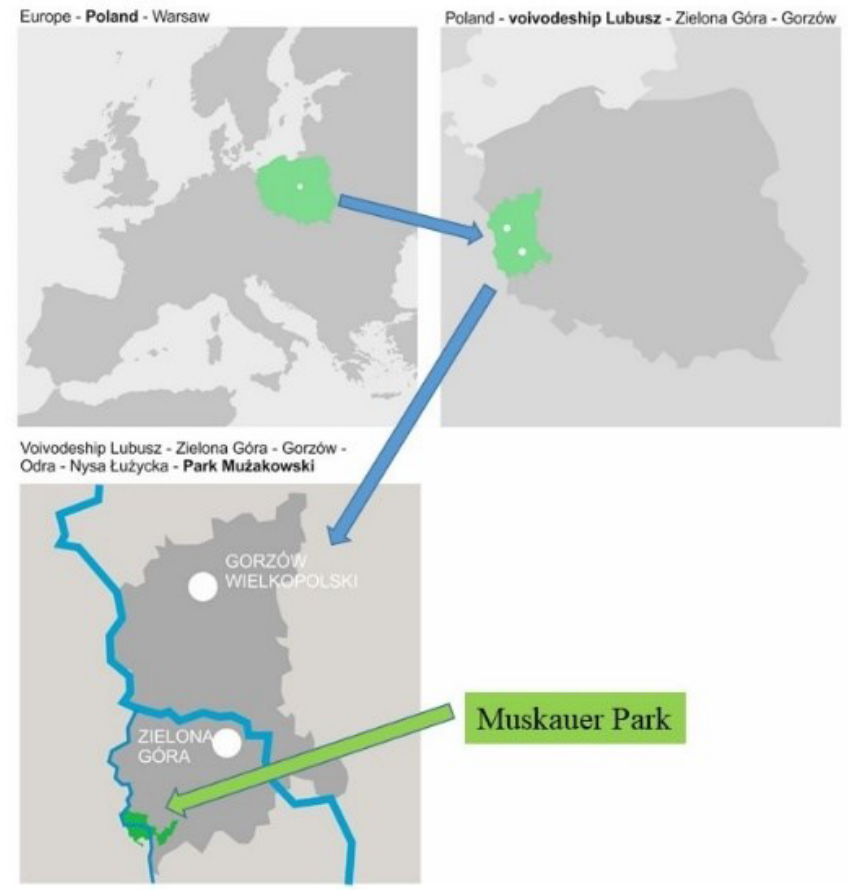

Fig. 4. The location of the study area, prepared by the author.
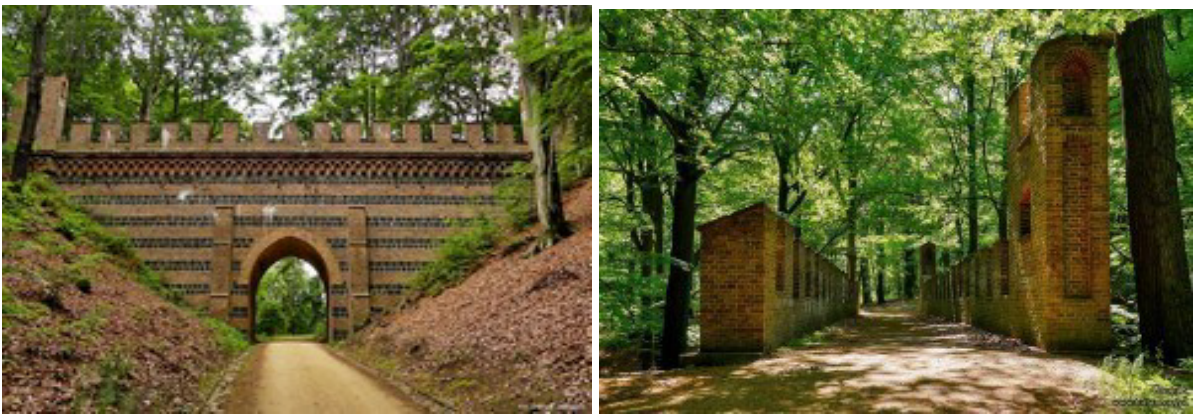

Fig. 5. The object subjected to measurements, http://podrozestarszegopana.radom.pl/park/index.html, https://tuitam.org.pl/bad-muskau-park-muzakowski/.

The execution of the task in numerical terms consisted in determination of the unknowns, which were the horizontal displacements $\Delta x$ and $\Delta y$ and the vertical displacements $\Delta h$ of the 
measurement and control network points located on the object, including the accuracy characteristics of these displacements. The objective of the measurements was both to determine displacements on the footbridge pavement and deviations from flatness and verticality of the footbridge walls. The measurements were carried out with the use of a Leica TCRP $1203+$ scanning station, a modern robotic total station with a Power Search function with a range of up to $1000 \mathrm{~m}$, where a moving laser beam finds a reflector, then an ATR device aims precisely at the prisms. Differences in the height of the points of the measurement and control network located on the pavement of the object were measured using a Leica DNA03 precision levelling instrument that can provide an accuracy of $0.3 \mathrm{~mm}$ from two consecutive levelling measurements of a length of $1 \mathrm{~km}$.

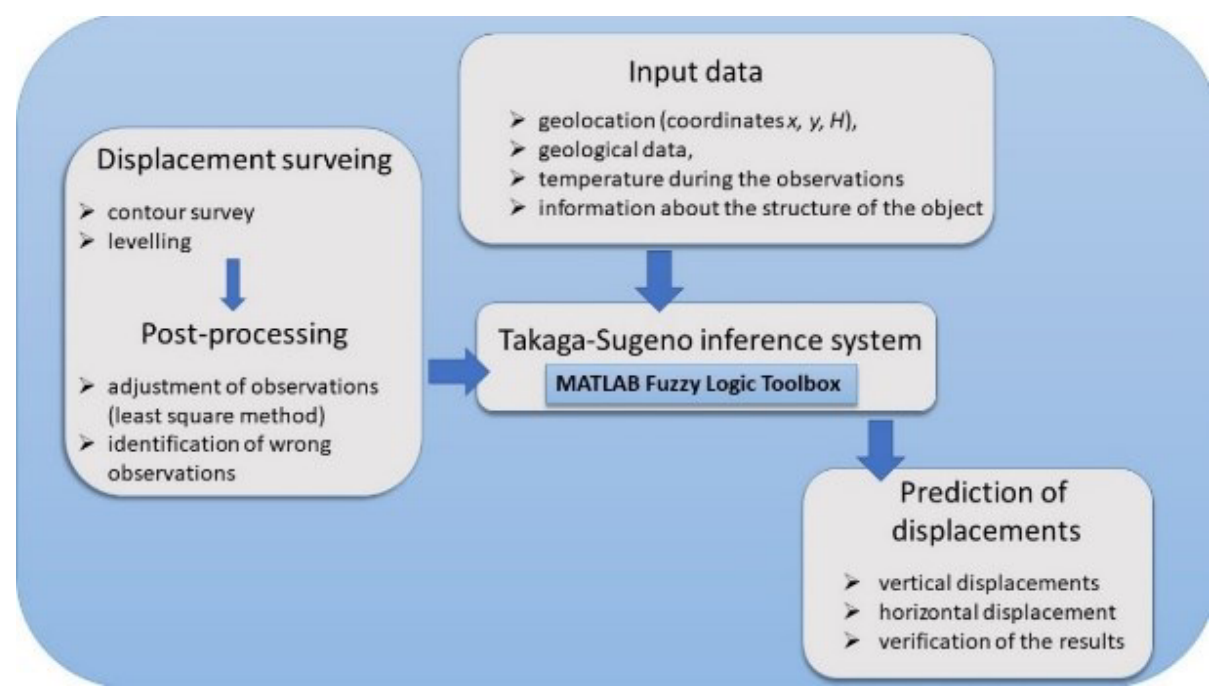

Fig. 6. The location of the study area, prepared by the author.

The results of the measurements were appropriately studied, which consisted in adjusting the observations and eliminating the outliers. Horizontal and vertical displacements were determined using the least square method with the assumption that observation errors were in normal distribution. This approach means that horizontal displacements are in normal distribution in relation to their expected values. From the mathematical point of view, the application of the neuro-fuzzy system for the problem in question aims to optimize the function as a measure of error between the input signals (components of the displacement vector) and the reference signals, which are the values of horizontal and vertical displacements that have been determined. A diagram of the execution of the task is presented in Fig. 6.

The geometrical condition of the object was determined for 14 measurement epochs and on this basis displacement was predicted for the $15^{\text {th }}$ epoch with the use of a combination of a neural network and a fuzzy system. The input set consisted of the following data for each point of the measurement and control network (130 points): geolocation (coordinates $x, y, H)$, geological data, temperature during the observations and information about the structure of the object. A model built in this way takes into account a lot of information predicting the values of displacements at particular points. The results of the prediction of vertical and horizontal displacements are presented in Fig. 7a and Fig. 7b. 

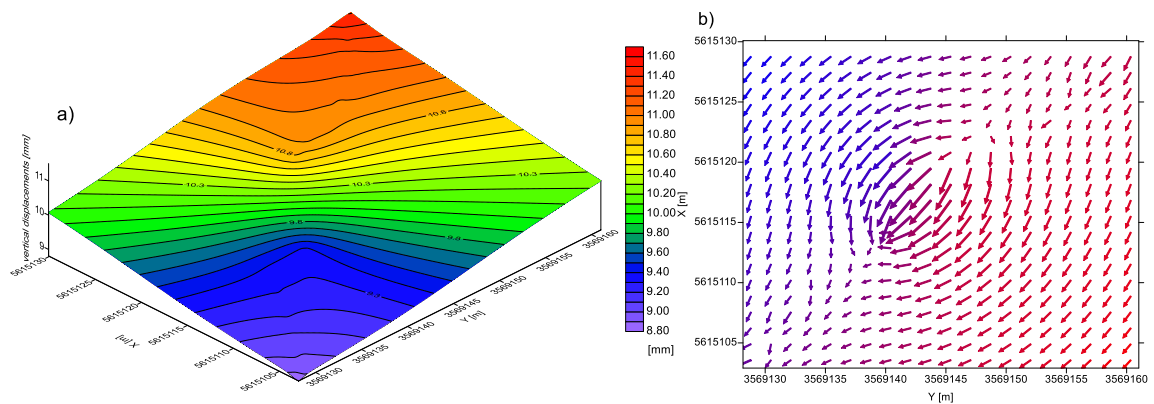

Fig. 7. The horizontal (a) and vertical (b) displacements obtained for the $15^{\text {th }}$ measurement epoch, prepared by the author.

Obviously, in order to check the correctness of the displacement prediction, the results were compared with the results of classical geodetic measurements. In the case of vertical displacements, the average displacement prediction error was $m_{H}= \pm 0.21 \mathrm{~mm}$, and for horizontal displacements this error was $m_{x}= \pm 1.7 \mathrm{~mm}$ and $m_{y}= \pm 2.5 \mathrm{~mm}$. Differences in vertical and horizontal displacements obtained from classical geodetic measurements and from the neuro-fuzzy system for selected points of the measurement and control network are shown in Fig. 8 and Fig. 9.

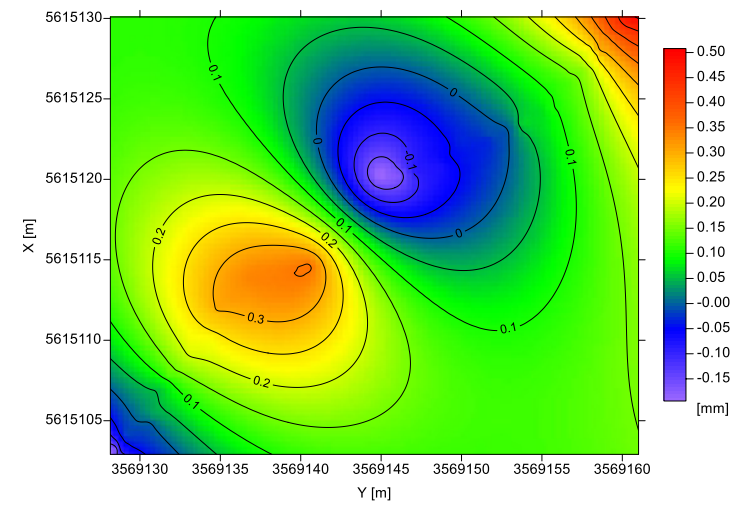

Fig. 8. Differences in vertical displacements obtained from classical geodetic measurements and from the neuro-fuzzy system, prepared by the author.

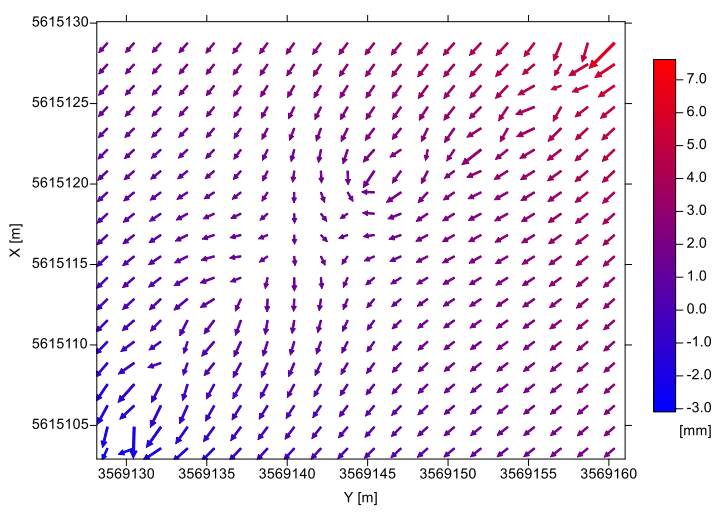

Fig. 9. Differences in horizontal displacements obtained from classical geodetic measurements and from the neuro-fuzzy system, prepared by the author. 


\section{Discussion}

The main objective of the paper was to show the possibility of using artificial intelligence, in particular neuro-fuzzy systems, to process the results of geodetic measurements in order to determine displacements and deformations of engineering structures. Based on the results, it is possible to state that artificial intelligence can be used to solve engineering problems. In the case of fuzzy systems, the basic problem is to obtain a set of conditional rules "if-then". By combining neural networks and fuzzy systems, we use the ability of neural networks to learn and to generalize the acquired knowledge. This knowledge is used to initiate parameters of the neural-fuzzy system that is then trained with the use of measurement data (usually in numerical form).

A neural-fuzzy system based on the assumptions of the Takaga-Sugenao inference system is a combination of simple models (usually linear), and the training process itself is based on minimization of the objective function. This approach enables the use of gradient optimization methods, which are simple in numerical implementation and bring good results in a short time. Obviously, other training methods can also be used in the training process: the method based on parallel optimization of local and global indicators or the deterministic annealing method $[28,29]$. These methods will be the subject of future research in terms of their applicability to problems related to classical measurements and terrestrial and aerial laser scanning.

Artificial intelligence can be used in many fields of knowledge, also in technical sciences. It enables construction of models of phenomena and processes that are difficult to describe mathematically. Fuzzy and neuro-fuzzy systems are also used to assess the environmental conditions of soil in a particular area with the use of data obtained from the GIS or by remote sensing [30], to build an intelligent navigation system based on integrated use of the GPS global positioning system [31] and to model responses of buildings to vibrations caused by earthquakes [32]. Such a wide use of fuzzy and neuro-fuzzy systems results from their ability to approximate step functions and to represent linguistic rules. It has also been proved that they can be used in broadly understood civil engineering, environmental engineering, remote sensing, GPS systems and spatial information systems

\section{Conclusions}

A combination of neural networks and fuzzy systems can be used in many fields of knowledge, including broadly understood civil engineering. The approach presented in the paper made it possible to assess the impact of measurement errors on the values of horizontal displacements of points in a measurement and control geodetic network and to determine the displacement values of these points.

The displacement values obtained with the use of the neuro-fuzzy system are characterized by smaller errors than the displacement values obtained from the measurements. Moreover, this system enables determination of the cause and effect relationship between the input and the output of the system because knowledge acquired by the neuro-fuzzy system is legible and represented in a qualitative form, which is important for example when expert systems are designed. 


\section{References}

1. Z. Huijbregts, R.P. Kramer, M.H.J. Martens, A.W.M. van Schijndel, H.L. Schellen, Build. Environ., 55, pp. 43-56 (2012)

2. A. Malinowska, R. Hejmanowski, Int. J. Rock Mech. Min. Sci., 47(2), pp. 238-245 (2010)

3. S.V. Usanov, V.I. Ruchkin, O.D. Zheltysheva, J. Min. Sci., 51(4), pp. 724-729 (2015)

4. R. Kadaj, Modele, metody $i$ algorytmy obliczeniowe sieci kinematycznych w geodezyjnych pomiar przemieszczeń i doksztatceń obiektów (Wydawnictwo Akademii Rolniczej, Kraków, 1998) [in Polish]

5. J. Zaczek-Peplinska, K. Podawca, K. Karsznia, Bulletin Of The Polish Academy of Sciences-Technical Sciences 68(1), pp. 87-98 (2018) [in Polish]

6. G. Oleniacz, I. Skrzypczak, L. Sleczka, T. Świętoń, M. Rymar, Reports on Geodesy and Geoinformatics 103(1), pp. 38-45 (2017)

7. G. Oleniacz, I. Skrzypczak, T. Świętoń, Civ. and Environ Eng. Rep., 24(1), pp. 39-45 (2017)

8. N. Wawrzyniak, A. Stateczny, Pol. Marit. Res. 25(97), pp. 5-13 (2018)

9. V.T. Bickel, A. Manconi, F. Amann, Remote Sens., 10(6), 865 (2018)

10. J.K. Kazak, Sustainability, 10(4), 1083 (2018)

11. S. Szewrański, J. Kazak, R. Żmuda, R. Wawer, Pol. J. Environ. Stud., 26(5), pp. 2239-2248 (2017)

12. B. Mitka, M. Pluta, Proceedings of $16^{\text {th }}$ International Multidisciplinary Scientific GeoConferences SGEM, 2(2), pp. 847-854 (2016)

13. P. Kalpa, B. Mitka, M. Zygmunt, Proceedings of WMESS Conf. Series: Earth and Enviromental Science, 95 (2017)

14. R. Tadeusiewicz, T. Gąciarz, B. Borowik, B. Leper, Odkrywanie właściwości sieci neuronowych przy użyciu programów C\# (Kraków: Polska Akademia Umiejętności, Poland, 2007) [in Polish]

15. W. Duch, J. Korbicz, L. Rutkowski, R. Tadeusiewicz, Sieci neuronowe (Akademicka Oficyna Wydawnicza Exit, Warszawa, 2000) [in Polish]

16. D. Venkata Ratnam, G. Vindhya, J.R.K. Kumar, Geod. Geodyn., 8(5), pp. 305-310 (2017)

17. Y. Lei, D. Zhao, H. Cai, Geod. Geodyn., 62(2), pp. 151-159, (2015)

18. M. Mrówczyńska, Studium nad doborem metod inteligencji numerycznej do rozwiązywania problemów z geodezji inżynieryjnej (Zielona Góra: Oficyna Wydawnicza Uniwersytetu Zielonogórskiego, 2015) [in Polish]

19. M. Mrówczyńska, J. Gil, Czasopismo Techniczne: Środowisko 2, pp. 215-221 (2008) [in Polish]

20. Y. Ning, J. Wang, H. Han, X. Tan, T. Liu, T., Sensors, 18, 9 (2018)

21. R. Banerjee, P.K. Srivastava, A.W.G. Pike, G.P. Petropoulos, ISPRS Int. J. GeoInf. 7(8), 326 (2018)

22. A.S. Loron, M.S. Loron, G. Peyvandi, Tehnički Vjesnik 22(2), pp. 383-389 (2015)

23. L. Rutkowski, Metody i techniki sztucznej inteligencji (Wydawnictwo Naukowe PWN, Warszawa, 2009)

24. B. Sun, Ch. Jiang, M. Li, Sensors 16, 11 (2016) 
25. M. Juszczyk, A. Lesniak, K. Zima, Complexity (2018)

26. A. Beycioglu, A. Gültekin, H.Y. Aruntas, O. Gencel, M. Dobiszewska, W. Brostow, Comput and Concrete 20(2), pp. 247-255 (2017)

27. J. Koźma, Przegląd Geologiczny, 59(4), pp. 276-290 (2011)

28. F. Serdio, E. Lughofer, A.C. Zavoianu, K. Pichler, M. Pichler, T. Buchegger, H. Efendic, Appl. Soft Comput., 51, pp. 60-82 (2017)

29. A. Rao, D. Miller, K. Rose, A. Gersho, IEEE Trans. Sig. Process. 45(11), pp. 2811-2820 (1997)

30. A.X. Zhu, B. Hudson, J. Burt, K. Lubich, D. Simonson, Soil Sci. Soc. Am. J. 65, pp. 1463-1472 (2001)

31. D. Loebis, R. Sutton, J. Chudley, W. Naeem, Control Eng. Pract. 12(12), pp. 1531-1539 (2004)

32. S. Pourzeynali, H.H. Lavasani, A.H. Modarayi, Eng. Struct. 29(3), pp. 346-357 (2007) 